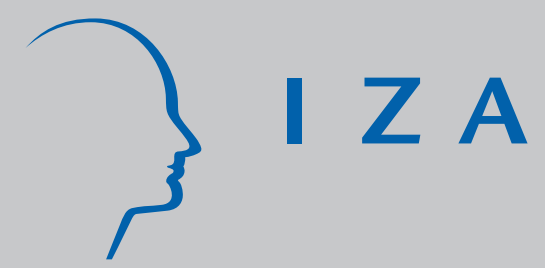

IZA DP No. 8953

Communication and Coordination in a Two-Stage Game

Tjaša Bjedov

Thierry Madiès

Marie Claire Villeval

March 2015

Forschungsinstitut zur Zukunft der Arbeit Institute for the Study of Labor 


\title{
Communication and Coordination in a Two-Stage Game
}

\author{
Tjaša Bjedov \\ University of Fribourg, \\ Université de Lyon, CNRS, GATE \\ Thierry Madiès \\ University of Fribourg \\ Marie Claire Villeval \\ Université de Lyon, CNRS, GATE \\ and IZA
}

Discussion Paper No. 8953

March 2015

\author{
IZA \\ P.O. Box 7240 \\ 53072 Bonn \\ Germany \\ Phone: $+49-228-3894-0$ \\ Fax: +49-228-3894-180 \\ E-mail: iza@iza.org
}

\begin{abstract}
Any opinions expressed here are those of the author(s) and not those of IZA. Research published in this series may include views on policy, but the institute itself takes no institutional policy positions. The IZA research network is committed to the IZA Guiding Principles of Research Integrity.

The Institute for the Study of Labor (IZA) in Bonn is a local and virtual international research center and a place of communication between science, politics and business. IZA is an independent nonprofit organization supported by Deutsche Post Foundation. The center is associated with the University of Bonn and offers a stimulating research environment through its international network, workshops and conferences, data service, project support, research visits and doctoral program. IZA engages in (i) original and internationally competitive research in all fields of labor economics, (ii) development of policy concepts, and (iii) dissemination of research results and concepts to the interested public.
\end{abstract}

IZA Discussion Papers often represent preliminary work and are circulated to encourage discussion. Citation of such a paper should account for its provisional character. A revised version may be available directly from the author. 


\section{ABSTRACT}

\section{Communication and Coordination in a Two-Stage Game*}

We study the impact of communication on behavior in a two-stage coordination game with asymmetric payoffs. We test experimentally whether individuals can avoid a head-to-head confrontation by means of coordinated strategies. In particular we analyze whether and how quickly a conflict-avoidance take-turn strategy can emerge. First, our results show that players learn to solve the conflict by choosing opposite options at both stages of the game. Second, many adopt a take-turn strategy to sustain coordination over time and alleviate the inequality induced by the asymmetry of payoffs. Third, communication increases the likelihood of conflict resolution even when a single pair member has the right to communicate.

JEL Classification: C91, D74, L15, H71

Keywords: coordination, communication, turn taking, conflict, experiment

Corresponding author:

Marie Claire Villeval

CNRS, GATE Lyon St Etienne

93, Chemin des Mouilles

F-69130, Ecully

France

E-mail: villeval@gate.cnrs.fr

\footnotetext{
* We are grateful to Quentin Thévenet who programmed this experiment, Zhixin Dai for research assistance, and Philippe Solal for useful discussions. This research has been supported by a grant from the University of Fribourg and was performed within the framework of the LABEX CORTEX (ANR-11- LABX-0042) of Université de Lyon, within the program "Investissements d'Avenir" (ANR-11IDEX-007) operated by the French National Research Agency (ANR).
} 


\section{Introduction}

Coordination failures are frequent in organizations and lead to huge losses of efficiency. Several studies have shown that communication can alleviate coordination failures, both when the players' interests are aligned (Cooper et al., 1992; Crawford, 1998; Blume and Ortmann, 2007) and when they are not (Cooper et al., 1989; Dickhaut et al., 1995; Duffy and Feltovich, 2002; Duffy and Hopkins, 2005; Cason and Mui, 2014). In particular, the asymmetry of payoffs between two players usually generates a conflict because both have an incentive to select the option that maximizes their own earnings. To solve the conflict, one player has to be accommodating and accept to play the option that earns him a lower payoff. Turn taking is a coordination strategy that is used to solve the coordination problem in repeated games (Bornstein et al., 1997; Bashkar, 2000; Helbing et al., 2005; Lau and Mui, 2008, 2012; Kaplan and Ruffle, 2012; Bruttel and Güth, 2013; Cason et al., 2013). Turn taking, where each player alternates the good and the bad turns, can maximize efficiency while minimizing inequality in the long run. ${ }^{1}$ Communication may also help people to overcome these conflicts. Only a few papers have, however, considered turn taking and communication simultaneously (Zillante, 2011; Leibbrandt and Sääksvuori, 2012; Evans et al., 2013). Yet, communication might help players to learn the strategy more quickly and to decide who should take the first advantage. Moreover, the literature on coordination failures has mainly considered one-stage games. Are communication and turn taking as effective when a game is two-staged?

\footnotetext{
${ }^{1}$ One can find several examples of turn taking strategies in real settings. Turn taking is indeed a frequent pattern in conversation, driving, product release, dividing household chores, etc. Lau and Mui (2012) give examples of common pool resources dilemmas and recall that Berkes (1992) reports examples from fishermen in Turkey using taking-turn strategies to allocate fishing spots and that Ostrom (1990) evokes rotation schemes in Spain and the Philippines for the use of irrigation systems.
} 
Our aim is to study by means of a laboratory experiment the impact of cheap talk communication and the emergence of turn taking in a symmetric two-player two-stage coordination game with asymmetric payoffs. A typical illustration of this type of games is the vertical differentiation model formalized by Gabszewicz and Thisse (1979) and Shaked and Sutton (1982) where firms can avoid price wars in the second stage of their interactions by offering goods of different quality levels in the first stage. Another example is the regional fiscal competition model (Justman et al., 2005) where regions have to decide first on how much to invest in infrastructures to attract firms and next, they have to design their tax policy. In this situation, if both regions are unable to diffentiate in terms of quality of infrastructures in the first stage, they will start a tax war in the second stage to attact firms, with deleterious effects on profits.

To reproduce this type of strategic situation, in the first stage of our finitely repeated two-stage coordination game with asymmetric payoffs, two players have to choose independently and simultaneously between two options, knowing that their decisions will determine the options that will be available in the second stage and thereby the attainable payoffs. In the second stage, after being informed on the other player's choice in the first stage players have to choose independently and simultaneously between two new options. Payoffs are determined and distributed to players only at the end of the second stage. The game has two Subgame Perfect Nash Equilibria. If both players opt in the first stage for the option that maximize their own payoff and disregard the payoff of their partner, they will have to choose in the second stage between two options with conflicting payoffs but which, in any case, will earn them less than if they were able to differentiate their choices in the first stage. On the opposite, coordination - corresponding to the social optimum - is 
achieved when the two players select opposite options in each stage. In our setting this leads one player to earn more than the other one from both stages.

Our experimental design, involving repeated interactions in fixed pairs during 20 periods aims at testing whether players learn using strategies that avoid a head-to-head confrontation and allow them to coordinate on opposite choices in both stages. In particular, we examine how frequently partners adopt a turn taking strategy - meaning that each player takes turn over periods as the high earnings player - in order to maximize efficiency and reduce payoffs inequality in the long run.

We hypothesize that pre-play communication may facilitate the use of a turn taking strategy in our two-stage game. To test this hypothesis, we introduced cheap talk communication (Farrel and Rabin, 1996) in some treatments. We implemented a two-way communication treatment (Two-Way, hereafter) and a one-way communication treatment (One-Way, hereafter). In the Two-Way treatment, subjects are allowed to exchange messages via a chat box for a minute at the beginning of each period. In the One-Way treatment only one of the two players -always the same- is allowed to send messages. The ability to send messages is determined by the relative performance of each player in a preliminary task. Endowing only one player with the right to communicate aims at testing whether this player takes advantage of his higher status to increase his claims, possibly changing the frequency of alternation between periods. ${ }^{2}$

Our main results are threefold. First, in the absence of communication almost half of the groups selected simultaneously identical options at both stages of the game and consequently failed to solve the conflict. Our second finding is that some groups learned turn taking over time, which permitted a durable resolution of the conflict. The third result is

\footnotetext{
${ }^{2}$ Early studies of one-way vs. two-way communication in simple coordination games (Cooper et al., 1992) and Battle-of-the-Sexes games have shown that two-way communication is more able to alleviate coordination failures than the one-way communication.
} 
that introducing two-way communication increased to $91 \%$ of the groups the likelihood of conflict resolution by allowing players to implement immediately a systematic and durable turn taking strategy. $85.86 \%$ of the groups played the social optimum. Finally, endowing only one player with the right to send messages affected neither the likelihood of achieving coordination on the socially optimal outcome, nor the frequency of alternation in taking turn. Indeed, in the One-Way treatment the social optimum was played in $87 \%$ of the observations and $77 \%$ of the groups took turn. Overall, we show that in complex two-stage coordination situations where inequality is unavoidable, communication can alleviate conflicts and increase efficiency provided relative positions can be exchanged in a fair way.

The remaining part of the paper is organized as follows: Section 2 reviews briefly the related literature. Section 3 describes the theoretical background and the experimental design and procedures. Section 4 presents and discusses our results. Section 5 concludes.

\section{Related Literature}

While communication in static games has been early and widely studied in experimental economics, ${ }^{3}$ there are much less studies on communication in two-stage games. An exception is Andersson and Wengström (2011) who test the impact of pre-play and intraplay communication between the stages of the game on cooperation. The payoffs of the game are such that players can sustain cooperation in a prisoner's dilemma played in the first stage by threatening to play the inferior equilibrium in a second stage coordination game with Pareto-ranked multiple equilibria. They find that pre-play communication increases cooperation but its effect is significantly reduced when intra-play communication

\footnotetext{
${ }^{3}$ See Isaac and Plott (1981), Isaac et al. (1984) and Isaac and Walker (1985) for experiments on the impact of face-to-face communication on bidding behavior, Ledyard (1995) and Sally (1995) for surveys on communication in social dilemmas, Cooper et al. (1992), Crawford (1998), and Blume and Ortman (2007) for coordination games, Bochet et al. (2006) for public goods games. See Cason and Mui (2014) on the relative impact of repetition and communication in an indefinitely repeated Divide and Conquer game.
} 
is possible. With the same game setting, Cooper and Kuhn (2012) find, however, that adding intra-play communication to pre-play communication increases cooperation. This difference may derive from the fact that they use written free-form communication, while Andersson and Wengström (2011) implemented a structured communication where the only possible contents were the intended action choices.

A major difference with this previous literature is that the equilibrium payoffs of our two-stage game are asymmetric while in the previous studies payoffs were equal in equilibrium. Another difference is that while these studies used two successive different games, in our game the second stage is nested in the first one. Indeed, payoffs in the game are determined only after the two stages have been completed. Another difference with previous studies is that we do not allow players to communicate between the two stages of the game, and we compare one-way and two-way communication.

In our game, successful coordination in the two stages implies that one of the partners has to sacrifice part of his earnings in both stages. Inequality aversion (Fehr and Schmidt, 1999) and guilt aversion (Charness and Dufwenberg, 2006) may create disutility if the same player has to sacrifice repeatedly. These preferences may motivate players to exchange between the good and the bad turn and to respect this rotation between the asymmetric outcomes over time. But turn taking may also be a profitable strategy for selfish players who want to establish a reputation of fairness in order to get higher payoffs than those obtained in case of conflict. The turn taking strategy has been modeled formally by Lau and Mui (2008, 2012) for respectively the battle-of-the-sexes game and for repeated symmetric $2 \times 2$ games (including chicken, common-pool-resources and prisoner's dilemma games) (see also Bhaskar, 2000). They show that, without communication, a turn taking equilibrium may exist for these classes of infinitely repeated games and that the expected time taken to reach 
such equilibrium increases in the degree of conflict between the players. Experimental evidence of turn taking has been shown in various repeated games such as a kind of chicken game (Bornstein et al., 1997), traffic game (Helbing et al., 2005), entry game with incomplete information (Kaplan and Ruffle, 2012), and a sequential public good game (Bruttel and Güth, 2013). Using an indefinitely repeated common-pool resource assignment game and a perfect stranger experimental design, Cason et al. (2013) show that players use an efficiency-enhancing turn taking strategy, learn fast this strategy, and teach it to other players, especially when the degree of conflict is lower. We contribute to this literature by considering a game with two nested stages, which may make the adoption of turn taking slower.

Only a few papers have considered turn taking and communication simultaneously as we are doing in our study. In a multi-player entry game, Zillante (2011) shows that a multiperiod signaling device (that differs from free-form communication) facilitates intertemporal cooperation and turn taking outcomes. Evans et al. (2013) find stronger evidence of turn taking in finitely repeated coordination games with dominant strategy equilibrium when cheap talk is allowed because communication stimulates pro-social behavior. Their results are robust to variations in the degree of conflict between players. Leibbrandt and Sääksvuori (2012) have shown that the structure of communication matters and that only unrestricted communication helps groups to take turn in winning a contest. We extend this literature by comparing one-way and two-way communication.

\section{Theoretical background and experimental design and procedures}

\subsection{The game}

We consider a two-player two-stage game with observable actions $\Gamma=\left[\{1,2\},\left\{\mathrm{u}_{\mathrm{i}}(\mathrm{s})\right\}^{2} \mathrm{i}=1\right.$, $\left.\left\{\mathrm{S}_{\mathrm{i}}\right\}^{2}{ }_{\mathrm{i}=1}\right]$ where $\mathrm{S}_{\mathrm{i}}$ is player $i$ 's strategy set and $\mathrm{u}_{\mathrm{i}}: \mathrm{S}_{\mathrm{r}} \times \mathrm{S}_{\mathrm{c}} \Rightarrow \mathbb{R}$ gives player $i$ 's utility for 
each profile $s$ of strategies. The game is characterized as a two-stage simultaneous-move game with complete but imperfect information. Let us consider the one-shot version of this game. Figure 1 presents the game with the payoff values used in the experiment. ${ }^{4}$

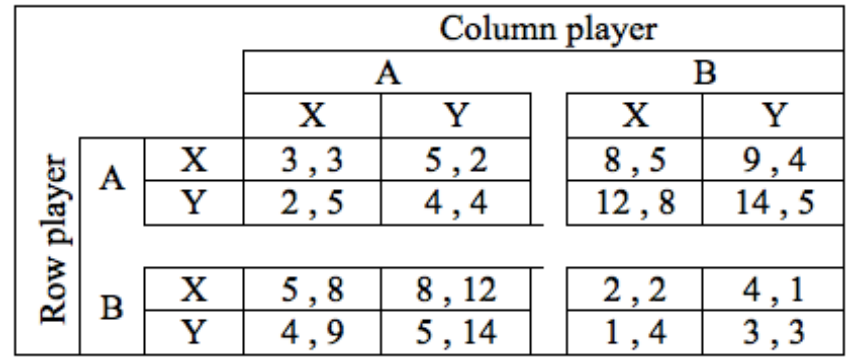

Fig. 1 The two-stage coordination game

In the first stage of the game, both players have to choose simultaneously and independently between options $\mathrm{A}$ and $\mathrm{B}$. In the second stage of the game, after being informed on the other player's first-stage choice, both players have to choose simultaneously and independently between options $\mathrm{X}$ and $\mathrm{Y}$ in the sub-game determined by the two players' choices in the first stage. Each player has 32 possible strategies: $S_{i}=\{(A, B) \times(X, Y) \times(X, Y)$ $\times(\mathrm{X}, \mathrm{Y}) \times(\mathrm{X}, \mathrm{Y})\} . \mathrm{S}_{\mathrm{r}} \times \mathrm{S}_{\mathrm{c}}$ results in a set of 10245 strategy profiles.

The matrix in Figure 1 displays the payoffs for all possible strategies for the row and column players. Payoffs are asymmetric in 12 cells out of 16, i.e. except when both players select the same options in both stages. Symmetric payoffs are smaller than those earned when players choose opposite options. ${ }^{5}$ The lower left and the upper right sub-matrices are symmetric, meaning that the same strategy leads to similar payoffs regardless of which player implements it. Payoffs are slightly higher in the upper left sub-matrix in comparison to the lower right-matrix, giving an advantage to option A in comparison to option B.

\footnotetext{
${ }^{4}$ The extensive form of the game can be found in Appendix 1.

5 Note that this situation is similar to a 'price war' which leads both players to earn the lowest possible earnings in the whole game.
} 
We use the Subgame Perfect Nash Equilibrium (SPNE) concept to solve this game. The game has five subgames, including four proper subgames. In each proper subgame both players have a dominant strategy. The row player's dominant strategy is option $\mathrm{X}$ in the first, third and fourth proper subgames, and option $\mathrm{Y}$ in the second proper subgame. The column player's dominant strategy is option $\mathrm{X}$ in the first, second and fourth proper subgames, and option $\mathrm{Y}$ in the third one. Each subgame entails a Nash equilibrium that is represented by the following action pairs $\left(A X_{r}, A X_{c}\right),\left(A Y_{r}, B X_{c}\right),\left(B X_{r}, A Y_{c}\right)$ and $\left(B X_{r}\right.$, $\left.B X_{c}\right)$. Applying backward induction, we find that only the action pairs $\left(A Y_{r}, B X_{c}\right)\left(B X_{r}\right.$, $\left.A Y_{c}\right)$ are subgame perfect. Figure 2 displays the reduced normal form of the game.

\begin{tabular}{|c|c|c|c|}
\hline \multirow{3}{*}{ 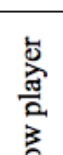 } & & \multicolumn{2}{|c|}{ Column player } \\
\hline & & A & B \\
\hline & A & 3,3 & 12,8 \\
\hline$\approx$ & B & 8,12 & 2,2 \\
\hline
\end{tabular}

Fig.2. Reduced normal form of the two-stage coordination game

The pure strategies Nash equilibria of the reduced form game are the action pairs $\left(A_{r}\right.$, $\left.B_{c}\right),\left(B_{r}, A_{c}\right)$ and the unique mixed strategy equilibrium is given by $\left(x_{r}=2 / 3 A_{r}+1 / 3 B_{r}\right.$, $\left.x_{c}=2 / 3 A_{c}+1 / 3 B_{c}\right)$. The two asymmetric outcomes $((A, B)$ and $(B, A)$ in Figure 2$)$ maximize total payoffs.

To sum up, the theoretical analysis of the game shows that players have to choose opposite options at both stages in order to earn the maximum possible payoff corresponding to the SPNE. It is easy to see that the SPNE of the game raise a conflict problem due to the asymmetry of payoffs.

Let us now consider the repeated version of this game. Players may try to solve the conflict by means of a turn taking strategy with a randomization in the first period (that can be avoided if communication is possible), and then a rotation between the asymmetric outcomes, with each player choosing the actions chosen by the other player in the previous 
period. If players do not deviate from this strategy, turn taking may last. Lau and Mui (2012) demonstrate how such a strategy profile can be supported as a subgame perfect equilibrium in a symmetric infinite horizon repeated game, if this strategy profile is unique and symmetric.

\subsection{Experimental design}

The experiment consists of three treatments and we used a between-subject design.

\section{Baseline treatment}

The Baseline treatment consists of 20 periods of the two-stage coordination game described in sub-section 3.1. We pair participants at the beginning of a session and it is made common knowledge that pairs remain fixed throughout the session. Using a partner matching protocol allows us to study inter-temporal coordination within pairs.

Each period is constructed as follows. Knowing the whole payoff matrix for the two stages of the game, each participant has to choose simultaneously and independently between options $\mathrm{A}$ and $\mathrm{B}$. Then, after receiving a feedback on the choice of his coparticipant, each player has to choose between options $\mathrm{X}$ and $\mathrm{Y}$. Then, participants are informed on their co-player's second choice and payoffs are displayed. Participants have also an opportunity to fill out a history table on a sheet of paper to keep track of previous plays and payoffs.

\section{The communication treatments}

The Two-Way communication treatment is similar to the Baseline, except that in this treatment players are allowed to exchange free-form messages during one minute at the beginning of the first stage of each period, using a chat box. Communication is not permitted between the two stages. Messages are free, except for the usual rules preserving anonymity 
and decent language. This treatment aims at testing whether individuals learn more rapidly to coordinate on the SPNE, in particular by using a turn taking strategy.

In the One-Way treatment, only one player in each pair is allowed to send messages and thus communication is limited to 20 seconds. To designate this player, we added a preliminary part in which participants have to perform a memory task during five minutes, before receiving instructions for the main game. ${ }^{6}$ The task is not incentivized, but participants are informed that their performance will be used to assign roles in the next part of the experiment. After five minutes, we compare the relative performance of participants and divide them into two equal groups. Players are informed that the computer program then creates pairs composed of one player with median or above-median performance and one player with below-median performance. In each pair, the player with above-median performance is allowed to send messages throughout the session.

This treatment aims at testing how endowing one of the two players with the right to communicate affects coordination. In particular we test if it motivates the player who got a higher status to try to keep a higher share of the payoffs, for example by proposing a less frequent rotation in turn taking compared to the previous treatment.

\section{Elicitation of individual characteristics}

Individual characteristics may ease or hamper coordination. We have therefore measured some of them. In particular, we elicited risk attitudes at the beginning of the sessions, using the procedure of Gneezy and Potters (1997) and Charness and Gneezy (2012). Each subject is endowed with 80 monetary units and has to choose how much to invest (between 0 and 80 ) in a risky investment. With $50 \%$ chance the investment returns 2.5 times its amount and with $50 \%$ chance it is lost. A risk neutral expected utility maximizer should invest all his

\footnotetext{
${ }^{6}$ The screen displays the back of sixteen cards and the task is to reform eight pairs with similar pictures by clicking on the cards and memorizing their pictures (see snapshots in the instructions in Appendix 2). Once the eight pairs are reformed, new cards are displayed on the screen.
} 
endowment, otherwise the individual is classified as risk averse. The participants received a feedback on the outcome of the random draw only at the end of the session. At the end of the experiment, a demographic questionnaire was also administered, including questions on gender, age, and relative wealth of the family compared to other students (on a scale from 0 for the poorer to 10 for the wealthier).

\subsection{Procedures}

The experiment was conducted at GATE-LAB, Lyon, France. 162 participants were recruited from local engineering and business schools, using ORSEE (Greiner, 2004). $50.62 \%$ of the participants are females. Their mean age is 25 years (S.D. $=9.12)$, their mean relative wealth 5.14 (S.D.=1.88), and their mean investment in the risky asset is 45.33 $($ S.D. $=22.69)$ showing evidence of risk aversion. Three sessions per treatment were organized, with 56, 44, and 62 participants in the Baseline, the Two-Way, and the One-Way treatments, respectively. The experiment was computerized using z-Tree (Fischbacher, 2007).

Upon arrival, participants were randomly assigned to a computer after drawing a tag from an opaque bag. Sets of instructions were distributed after each part and read aloud. The payoff matrix (Fig.1) was distributed with the instructions (see Appendix 2). To facilitate its reading, each player was identified with a color (red for the row player and blue for the column player). In addition, we displayed the whole matrix at the beginning of each first stage and the relevant sub-matrix at the beginning of each second stage on the computer screens. Therefore, subjects had in front of them all relevant information when making their decisions. The understanding of participants was checked by means of a questionnaire and all questions were answered in private.

On average a session lasted 90 minutes, including payment. The participants were paid the sum of their earnings in each period in addition to their earnings from the risk elicitation 
task, at the rate of 1 experimental currency unit $=0.05$ Euro. In addition, they were paid a $€ 4$ show-up fee. On average, participants earned $€ 17.20$ (S.D.=3.30). Payments were made individually in cash and in private in a separate room.

\section{Results}

\subsection{Coordination}

We define coordination as a situation in which the two players select opposite options at both stages of the game. To study how groups coordinate, we focus on the following three situations. First, the Subgame Perfect Nash Equilibrium that requires that the two players choose opposite options in the two stages of the game: they play A and B in the first stage and $\mathrm{Y}$ and $\mathrm{X}$, respectively, in the second stage (which corresponds to their dominant strategy in the symmetric subgames two and three, see Figure 1). Second, the situation when the two players fail to coordinate in the first stage (both play A or B) and play their dominant strategy in the second stage (both choose $\mathrm{X}$, which corresponds to playing the Nash equilibrium in subgames one and four), which leads both subjects to jointly earn the lowest possible payoffs. The third relevant situation might be considered as a fallback situation and it occurs when the two players make the same choice in the first stage (both play A or B) but do not play the Nash equilibrium in subgames one and four (both choose Y), in order to attain the Pareto optimal outcome in these subgames. In this last case, both subjects earn a slightly higher payoff than that obtained when playing the Nash Equilibrium.

Only a few groups, after selecting opposite options in the first-stage of the game, opted for identical options in the second-stage $(6.61 \%$ of the groups in the Baseline, $4.10 \%$ in the Two-Way and $4.83 \%$ in the One-Way). It is clear that the first-stage choices are crucial to the success of coordination in pairs. This is why we first report the analysis of behavior in the first stage before analyzing the data for the two stages taken together. 


\section{Differentiation in the first stage of the game}

In the first stage of the Baseline, both players choose option A in $32.86 \%$ of the cases (184 /560 pairs*periods) and both choose option $B$ in only $7.14 \%$ of the cases $(40 / 560$ pairs*periods). Both players' preference for option A is not surprising since it allows them to avoid the proper game that leads to the lowest payoffs (the lower right proper subgame in Figure 1). Thus, players are able to differentiate in only $60 \%$ of the observations $(336 / 560$ pairs*periods) by choosing $\mathrm{AB}$ or $\mathrm{BA}$, which is a condition for reaching the SPNE. This reveals a high rate of coordination failures when communication is not possible.

The picture changes dramatically when communication is introduced. Indeed, the two players are able to differentiate in $90 \%$ of the cases (396/440) in the Two-Way treatment and in $92.17 \%$ of the cases $(553 / 600)$ in the One-Way treatment. The mean percentage of differentiated first-stage choices is significantly different in both the Two-Way and the OneWay treatments compared to the Baseline (two-tailed Mann-Whitney tests - MW, hereafterwith each pair's choices averaged over the 20 periods as an independent observation; $p<0.001$ in both treatments $)^{7}$. There is no significant difference between the two treatments with communication $(p=0.918)$.

Both players choose option $A$ in only $7.05 \%(31 / 440)$ and $6.5 \%(39 / 600)$ of the observations in the Two-Way and One-Way treatments, respectively. Again, these percentages are significantly different from those in the Baseline $(p<0.001$ in both cases), but they do not differ from each other $(p=0.977)$. The percentages of choices of option B by both players are respectively $2.95 \%(13 / 440)$ and $1.33 \%(8 / 600)$. These percentages do differ statistically from those in the Baseline ( $p=0.016$ and $p=0.003$, respectively) and but not from each other $(p=0.943)$. Thus, when they can discuss on a strategy (Two-Way

\footnotetext{
${ }^{7}$ Unless specified otherwise, all the non-parametric tests reported in this paper are two-tailed and each pair averaged across all periods give one independent observation.
} 
treatment) or communicate a strategy (One-Way treatment), players are most of the time able to implement the first condition for reaching the SPNE.

Individuals learn over time to differentiate their choice in the first stage of the game but learning is quicker when communication is possible. The three panels of Figure 3 display for each treatment the evolution of the distribution of first-stage choices in the pairs, by blocks of five periods. ${ }^{8}$

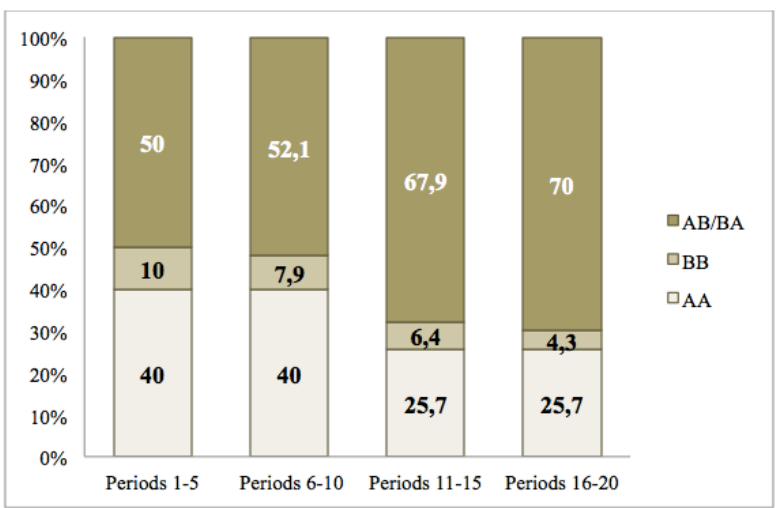

a) Baseline treatment

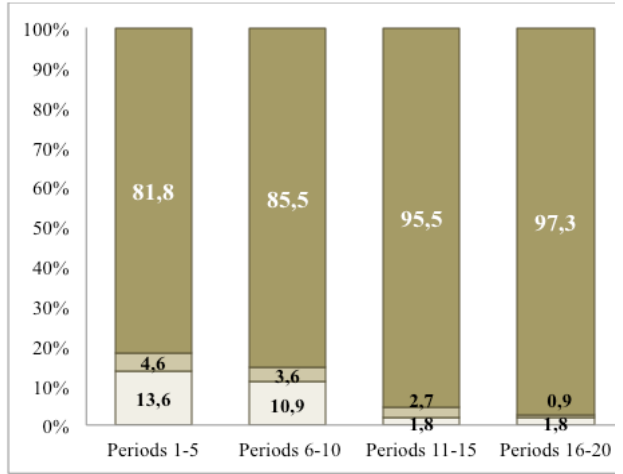

b) Two-Way treatment

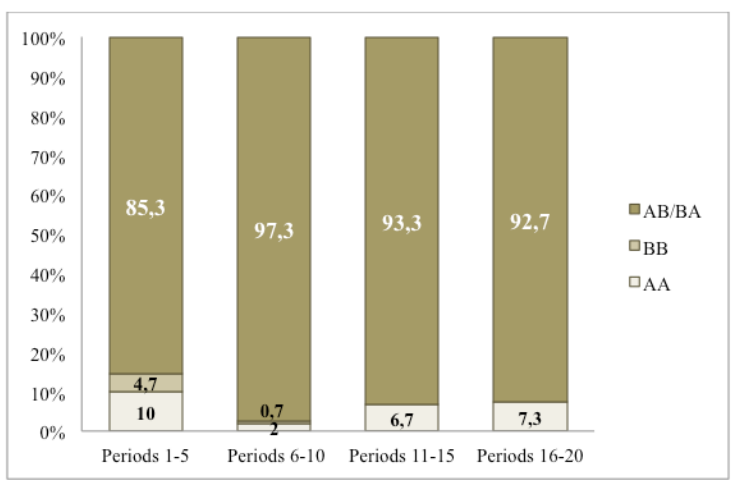

c) One-Way treatment

Figure 3. Distribution of first-stage pairs' choices, by block of periods and by treatment

Figure 3a shows that in the Baseline treatment, players are more likely to differentiate their first-stage decision in the last ten periods compared to the first ten. Only three groups were able to start differentiating their first stage choices in the first three periods and

\footnotetext{
${ }^{8}$ For more detailed information, Figures A1, A2 and A3 in Appendix 3 display the distribution of first-stage choices between A and B for each pair and each period, for each treatment respectively.
} 
continued throughout the game. Wilcoxon tests (W, hereafter) at the pair level indicate significant differences between the first ten and the last ten periods in the mean percentages of differentiated choices $(p=0.004)$, choice of option A by both players $(p=0.011)$, and choice of option B by both $(p=0.067)$. However, even in the last block of five periods, there are still $30 \%$ of the pairs that are not able to coordinate on opposite choices. In the absence of communication, it takes time for the players to learn differentiating their action. It is a standard result in coordination games but the difficulty is stronger here since one player has to accept to earn less in the anticipation of the second stage.

Learning occurs also in the communication treatments but it is more immediate. Wilcoxon tests indicate significant differences between the first ten and the last ten periods in the mean percentages of differentiated choices in the Two-Way and in the One-Way treatment $(p=0.002$ and $p=0.018$, respectively). In the Two-Way treatment we find significant differences in the mean percentages of choice of option A by both players $(p=0.001)$, but not in the mean percentages of joint choice of option $\mathrm{B}(p=0.392)$. The opposite results are found in the One-Way treatment ( $p=0.143$ and $p=0.005$, respectively). If learning occurs, 17 groups out of 22 in the Two-Way treatment and 23 groups out of 31 in the One-Way treatment were already able to make opposite first-stage choices in the first three periods.

\section{Overall coordination}

First-stage choices are a necessary but not a sufficient condition for the achievement of coordination. Even if only few groups failed to reach the SPNE after starting with opposit options, the anticipation of the consequences of the second-stage choices on the payoffs 
influcences first-stage decisions. Table 1 displays the distribution of these situations by treatment and by block of five periods, as we expect some learning to occur. ${ }^{9}$

Table 1. Summary statistics on coordination over time, by treatment and block of periods

\begin{tabular}{lccc}
\hline Treatments & Baseline & $\begin{array}{c}\text { Two-Way } \\
\text { communication }\end{array}$ & $\begin{array}{c}\text { One-Way } \\
\text { communication }\end{array}$ \\
\hline $\begin{array}{l}\text { Different options in both stages } \\
\text { (SPNE) } \text { AY and BX. BX and AY) }\end{array}$ & $299(53.39)$ & $377(85.68)^{* * *}$ & $537(86.61)^{* * *}$ \\
Periods 1-5 & $51(36.43)$ & $81(73.64)$ & $106(68.39)$ \\
Periods 6-10 & $65(46.43)$ & $89(80.91)$ & $144(92.90)$ \\
Periods 11-15 & $88(62.86)$ & $103(93.64)$ & $143(92.26)$ \\
Periods 16-20 & $95(67.86)$ & $104(94.55)$ & $144(92.90)$ \\
\hline Same option in stage 1 (A or B)+ & $116(20.71)$ & $11(2.50)^{* * *}$ & $18(2.90)^{* * *}$ \\
Nash equilibrium in stage 2 (X) & & & \\
Periods 1-5 & $29(20.71)$ & $3(2.73)$ & $7(4.52)$ \\
Periods 6-10 & $31(22.14)$ & $8(7.27)$ & $1(0.65)$ \\
Periods 11-15 & $27(19.29)$ & $0(-)$ & $3(1.94)$ \\
Periods 16-20 & $29(20.71)$ & $0(-)$ & $7(4.52)$ \\
\hline Same option in stage 1 (A or B) + & $28(5.00)$ & $15(3.41)^{n s}$ & $8(1.29)^{*}$ \\
Optimum in stage 2(Y) & $14(10.00)$ & $8(7.27)$ & $7(4.52)$ \\
Periods 1-5 & $11(7.86)$ & $4(3.64)$ & $1(0.65)$ \\
Periods 6-10 & $3(2.14)$ & $0(-)$ & $0(-)$ \\
Periods 11-15 & $0(-)$ & $3(2.73)$ & $0(-)$ \\
Periods 16-20 & $117(20.89)$ & $37(8.41)^{* * *}$ & $57(9.19)^{* * *}$ \\
\hline Other situations & & & \\
Periods 1-5 & $46(32.86)$ & $18(16.36)$ & $35(22.58)$ \\
Periods 6-10 & $33(23.57)$ & $9(8.18)$ & $9(5.81)$ \\
Periods 11-15 & $22(15.71)$ & $7(6.36)$ & $9(5.81)$ \\
Periods 16-20 & $16(11.43)$ & $3(2.73)$ & $4(2.58)$ \\
\hline Total number of observations & $560(100)$ & $440(100)$ & $620(100)$ \\
\hline
\end{tabular}

Note: The Table displays the number of observations, with the percentages represented by each category of situation in parentheses. $* * * * *$ and $*$ indicate significance levels at the $0.01,0.05$ and 0.1 levels respectively, and ${ }^{\text {ns }}$ indicates no significance in two-tailed Mann-Whitney tests in which we compare each treatment to the Baseline treatment. Each pair of subjects gives only one independent observation.

Table 1 shows that the players are able to coordinate on the SPNE in only $53.39 \%$ of the cases. When they are not able to differentiate their choices in the first stage, they are more likely to play the Nash equilibrium of the sub-game than the optimum $(20.71 \%$ vs. $5 \%$, respectively).

\footnotetext{
${ }^{9}$ For more detailed information, Figures B1, B2 and B3 in Appendix 3 display the strategies played by each pair of subjects in each period, for each treatment respectively.
} 
In contrast, communication makes coordination on the SPNE significantly more likely than in the Baseline (MW test, $p<0.001$ in both the Two-Way and One-Way treatments). Indeed, pairs are able to coordinate in $85.68 \%$ and $86.61 \%$ of the cases in the Two-Way and the One-Way treatments, respectively $(p=0.949)$. While the percentage of pairs that played the SPNE more than 10 periods in total was only $14 \%$ in the Baseline, it is $91 \%$ in the TwoWay treatment and $90 \%$ in the One-Way treatment. When pairs made the same choice in the first stage, players play also significantly differently the Nash equilibrium in the second stage compared to the Baseline $(p<0.001$ in both treatments). Indeed, this characterizes only $2.50 \%$ and $2.90 \%$ of the observations in the Two-Way and One-way treatments, respectively. A difference is found in the choice of the optimum in the second stage in pairwise comparisons for the One-Way treatment $(p=0.056)$ but not in the Two-Way treatment $(p=0.458)$. Finally, while there were more than $20 \%$ of the observations that could not be characterized in the Baseline, this represents less than $10 \%$ of the observations in the treatments with communication $(p<0.001)$.

Table 1 also reveals that some learning occurs. In the Baseline, the SPNE is played in $36.43 \%$ of the cases during the first five periods. This percentage increases to $46.43 \%$ in periods 6 to 10 and $62.86 \%$ in periods 11 to 15 to stabilize at $67.86 \%$ towards the end of the game. Pairs are significantly more likely to play the SPNE in the second part of the game than in the first one (W test, $p=0.004$ ). However, even in the last block of five periods, the number of pairs playing the SPNE remains different compared to both the Two-Way and the One-Way treatments (MW test, $p=0.001$ in both).

Coordination is much faster with communication. Indeed, in the Two-Way treatment the SPNE is already played $73.64 \%$ of the time in the first five periods and $68 \%$ of the pairs played the SPNE continuously after the third period. In the One-Way treatment the SPNE is 
already played in $68.39 \%$ of the time in the first five periods and among the 23 pairs who chose opposite options in the first stage, 22 selected also opposite options in the second stage in the first three periods. The SPNE is played in $92 \%$ of the cases in each of the three following blocks of periods. Pairs are also significantly more likely to play the SPNE in the second part of the game than in the first one (W test, $p=0.002$ in the Two-Way treatment, and $p=0.018$ in the One-Way treatment).

To complement this analysis, we now report the results of an econometric analysis.

Table 2 presents the estimates of Probit models in which the dependent variable is the probability for a pair of subjects to play the SPNE. Standard errors are clustered at the pair level since groups are fixed throughout the session. Model (1) pools the data of all treatments, model (2) considers the data from the Baseline, and model (3) the data from the treatments with communication. In model (1) the independent variables include dummies for treatments (the Baseline is the reference category). Model (3) includes a dummy variable for the One-Way treatment. In all models, the independent variables include a time trend and various mean individual characteristics of the pairs. The latter consist of the number of females in the pair, the mean wealth, the within-pair difference in wealth, the mean risk index and the within-pair difference in the risk index. Indeed, players with different characteristics matched in the same pair may possibly coordinate more easily. Table 2 reports marginal effects. 
Table 2. Determinants of the play of Subgame Perfect Nash Equilibrium

\begin{tabular}{lccc}
\hline & All treatments & $\begin{array}{c}\text { Baseline } \\
\text { treatment } \\
(1)\end{array}$ & $\begin{array}{c}\text { Communication } \\
\text { treatments } \\
(3)\end{array}$ \\
\hline Two-Way Treatment & $0.277(0.041)^{* * *}$ & - & - \\
One-Way Treatment & $0.241(0.039)^{* * *}$ & - & $0.000(0.041)$ \\
Period & $0.019(0.0024)^{* * *}$ & $0.023(0.005)^{* * *}$ & $0.014(0.002)^{* * *}$ \\
Number females in the pair & $-0.022(0.072)$ & $0.277(0.136)^{* *}$ & $-0.163(0.069)^{* *}$ \\
Mean relative wealth & $0.008(0.012)$ & $0.005(0.019)$ & $-0.003(0.013)$ \\
Within-pair difference in & $-0.000(0.013)$ & $0.014(0.022)$ & $-0.009(0.014)$ \\
wealth & & & \\
Mean risk attitude & $0.003(0.001)^{*}$ & $0.003(0.002)$ & $0.003(0.001)^{* *}$ \\
Within-pair difference in risk & $-0.000(0.001)$ & $-0.000(0.002)$ & $-0.001(0.000)$ \\
attitudes & & & \\
\hline Number of observations & 1620 & 560 & 1060 \\
Log-likelihood & -750.45688 & -359.14942 & -362.57027 \\
$p>$ chi2 & 0.0000 & 0.0004 & 0.0000 \\
Pseudo R2 & 0.1821 & 0.0713 & 0.1645 \\
\hline
\end{tabular}

Note: Marginal effects of a Probit model in which the dependent variable is probability for a pair of subjects to play the SPNE are reported. Robust standard errors are clustered at the pair level. ***, **,* indicate significance at the $0.01,0.05$, and 0.10 level, respectively.

The regressions reported in Table 2 confirm that the likelihood to play the SPNE is significantly higher in the two treatments with communication (model (1)). This result is in accordance with the literature showing that communication considerably increases the likelihood of coordination on an efficient equilibrium (Cooper et al., 1992; Blume and Ortmann, 2007; Brandts and Cooper, 2007). In contrast, model (3) shows that giving a stronger influence to one of the pair member does not affect coordination. The significant effect of the time trend shows evidence of learning within pairs. The marginal effect is especially large in the Baseline (model (2)). Interestingly, we find that pairs with more females are more likely to play the SPNE when communication is not available but not when communication is possible. A lower mean risk aversion increases the probability of playing the SPNE in communication treatments and when data of all treatments are pooled but the difference in the degree of risk aversion in the pair has no effect.

Result 1: In a two-stage game where the Subgame Perfect Nash Equilibrium requires that the two players make opposite choices in both stages and accept unequal payoffs, only half of the pairs are able to coordinate in the absence of communication. 
Result 2: Communication increases dramatically the probability of pairs to play the SPNE. Assigning to only one player the right to communicate does not affect this probability.

\subsection{Turn taking and submission}

In this last sub-section we examine two possible coordination strategies in pairs: turn taking and submission. Turn taking means that players exchange the bad turn (choosing option B that yields a payoff of $8 \mathrm{ECU}$ ) and the good turn (choosing option A that yields a payoff of 12 ECU) repeatedly (every period, every two, four, five or even after 10 periods). We impose that the strategy is observed for at least 10 periods to characterize the pair of players as turn takers. Submission is the opposite of turn taking: one pair member always keeps the bad turn for himself and leaves the good turn to his partner.

In the Baseline treatment, turn taking remains seldom and is applied by only 5 pairs out of $28(17.86 \%)$ continuously for at least 10 periods until the end of the game. ${ }^{10}$ One of these pairs was able to implement this strategy from the second period. On the opposite, two pairs play the SPNE repeatedly but never exchange turns, one player dominating the other one who makes an attempt to change turns but gives up rapidly.

Communication undeniably improves the probability of turn taking. The great majority of pairs take turns during at least 10 periods when communication is allowed $(90.90 \%$ and $77.41 \%$ of the pairs in the Two-Way and the One-Way treatments, respectively). These proportions are both significantly different from that in the Baseline (proportion tests, $\mathrm{p}<0.001)$, but not significantly different from each other $(p=0.305)$. In the Two-Way treatment, 20 pairs out of 22 have continuously exchanged their turns. Among these 20

\footnotetext{
${ }^{10}$ For more detailed information, Figures $\mathrm{C} 1, \mathrm{C} 2$ and $\mathrm{C} 3$ in Appendix 3 display the strategies played by each subject within each pair in each period, for each treatment respectively.
} 
pairs, 18 have exchanged their turns after each period and only two pairs exchanged turns after 10 periods. We do not find evidence of domination- submission in this treatment.

In the One-Way treatment, 24 pairs out of 31 have continuously exchanged their turns in at least 10 periods. ${ }^{11}$ Most of the groups exchange the good and bad turn after each period. The message sender monopolizes the good turn in only three pairs, and the player who cannot send a message accepts this submission without trying to punish his partner. The study of the communication content shows that in one pair the message sender mislead his partner, by making him believe that he would give him the good turn after 10 periods, what he eventually did not do. In two pairs, turn taking occurred not every period but after a first block of 10 periods. This obviously requires that the player who takes the first bad turn trusts the other player. This is why the message sender in both groups started with the bad turn.

The average difference of payoffs in absolute value between the treatments is $3.28,2.64$ and 3.98 ECU in respectively the Baseline, Two-Way and One-Way. Mann-Whitney tests indicate that there is a statistically significant difference between the Baseline and the communication treatments (MW tests, Baseline vs. Two-Way $p=0.001$, Baseline vers OneWay $p<0,001$ ) but that there is no difference betweent the two communication treatement (MW test, $p=0.8187$ ). Communication helps individual equalize long term payoffs by rotation between the good and the bad turn. Even if the mean duration of the turn taking strategy for those groups who are able to implement it during at leat 10 periods without any interruption is 16.20 periods in the Baseline, 17.40 in the Two-Way treatment and 18.70 in the One-Way treatment pairwise Mann-Whitney tests show that the mean duration in the

\footnotetext{
${ }^{11}$ Relaxing the definition by considering that players use turn taking when they alternate continuously during at least five periods instead of 10 does not make a difference: only 6 pairs out of 28 correspond to this larger definition in the Baseline, 21 out of 22 in the Two-Way treatment and 27 out of 31 in the One-Way treatment.
} 
Baseline is significantly different compared to both the Two-Way and the One-Way treatments ( $\mathrm{MW}$ tests, $p<0.001$ in both) but there is no difference between the two communication treatments ( $\mathrm{MW}$ test, $p=0.386$ ). This suggests that communication is not only crucial to initiate this strategy but also to sustain it.

To further investigate the determinants of turn taking we estimate Probit models in which the dependent variable takes value 1 if the pair has played a turn taking strategy for at least 10 periods in a row, and 0 otherwise. One pair gives only one observation in these models. Model (1) is for the whole sample, model (2) restricts the sample to the Baseline treatment and model (3) to the treatments with communication. For consistency, we add the same independent variables as in the regressions reported in Table 2, except for the time trend. Table 3 reports marginal effects.

Table 3. Determinants of the probability of pairs to use turn taking in at least 10 periods

\begin{tabular}{|c|c|c|c|}
\hline & $\begin{array}{l}\text { All treatments } \\
\text { (1) }\end{array}$ & $\begin{array}{l}\text { Baseline } \\
\text { treatment } \\
(2)\end{array}$ & $\begin{array}{c}\text { Communication } \\
\text { treatments } \\
(3)\end{array}$ \\
\hline One-Way Treatment & $0.568 * * *(0.094)$ & - & $-0.057(0.050)$ \\
\hline Two-Way Treatment & $0.564 * * *(0.85)$ & - & - \\
\hline Number of females in the pair & $-0.127(0.196)$ & $0.426 *(0.236)$ & $-0.226 * *(0.099)$ \\
\hline Mean relative wealth & $0.0199(0.031)$ & $0.045(0.032)$ & $-0.010(0.013)$ \\
\hline Within-pair difference in wealth & $-0.004(0.003)$ & $-0.003(0.025)$ & $-0.015(0.015)$ \\
\hline Mean risk attitude & $0.004(0.003)$ & $0.003(0.004)$ & $0.003 *(0.001)$ \\
\hline $\begin{array}{l}\text { Within-pair difference in risk } \\
\text { attitudes }\end{array}$ & $0.001(0.003)$ & $-0.004(0.003)$ & $0.001(0.001)$ \\
\hline Number of observations & 81 & 28 & 53 \\
\hline Log-likelihood & -31.934 & -9.871 & -15.107 \\
\hline$p>$ chi2 & $<0.001$ & 0.1127 & 0.1588 \\
\hline Pseudo R2 & 0.4019 & 0.2486 & 0.2697 \\
\hline
\end{tabular}

Note: Marginal effects of Probit regressions in which the dependent variable is the fact that the pair takes turn in at least 10 periods are reported. Robust standard errors are in parentheses. $* * *, * *, *$ indicate significance at the $0.01,0.05$, and 0.10 level, respectively.

Table 3 confirms that the two communication treatments significantly increase the probability of turn taking. In model (1)), a t-test comparing the two coefficients shows that there is no significant difference between the coefficients of the two communication 
treatments. $(p=0.380)$. Interestingly, model (3) indicates that pairs in which players are less risk averse have greater probability of turn taking.

To sum up, we have the following findings.

Result 3: In a two-stage game with a SPNE with asymmetric payoffs, less than one fifth of pairs use a turn taking strategy when no communication is allowed.

Result 4: Communication increases the ability of players to implement durably a turn taking strategy to coordinate on the SPNE. There is no difference between two-way and one-way modes of communication in the probability of turn taking.

Result 5: Communication is more crucial to initiate a turn taking strategy of coordination than to sustain it.

\section{Conclusion}

Our laboratory experiment investigates how individuals can coordinate in a two-stage game that captures some real features, like investment in infrastructure and fiscal competition between regions or vertical differentiation between firms. The literature has shown how frequent are coordination failures in one-stage games, and how communication can help individuals to coordinate, notably by implementing strategies like turn taking in order to reduce long-term payoff inequality. Our contribution is to study whether communication has the same ability to overcome coordination failures in a two-stage game where the Subgame Perfect Nash Equilibrium requires that the two players make opposite choices in both stages and accept unequal payoffs.

We find that coordination failures occur in almost half of the time and less than one fifth of pairs use a turn taking strategy to alleviate long-term payoff inequality. Communication increases dramatically coordination on the SPNE. This results from the fact that it increases the ability of players to initiate a turn taking strategy between the players. Its impacts is also important in sustaining it. Finally, allowing both players or only one player to send messages to his partner has no effect on the probability of using turn taking and 
coordinating on the SPNE. Indeed, in the One-Way treatment in one fourth $(25,81 \%)$ of the groups the player that could send the messages was also the one that started with the bad turn indicating the will of these players to implement turn taking.

By communicating together subjects were able to establish a long-lasting strategy that allowed them to increase efficiency and decrease inequality by exchanging their relative positions in a fair way. Our results show that communication is able to solve coordination conflicts even in more complex situations than in the one-stage games usually studied until now.

A natural extension of this research could aim at determining the frontiers of positive communication effects on conflict resolution. This would require strengthening the difficulty of finding a consensus in our two-stage game, for example by introducing a stronger conflict in the second stage of the game. The payoff structure could be modified such that the Subgame Perfect Equilibium no longer corresponds to the social optimum. Finally, the decisions could be made partially or completely irreversible so that the application of turn taking would become more complicated. 


\section{References}

Andersson, O. and Wengström, E. (2012). Credible Communication and Cooperation: Experimental Evidence for Multi-Stage Games. Journal of Economics Behavior and Organization, 81, 207-219.

Berkes, F., (1992). Success and failure in marine coastal fisheries of Turkey. In: Bromley, D. (ed.) Making the Commons Work: Theory, Practice, and Policy, 161-182. Institute for Contemporary Studies, San Francisco.

Bhaskar, V. (2000). Egalitarianism and Efficiency in Repeated Symmetric Games. Games and Economic Behavior, 32, 247-262.

Blume, A. and Ortman, A. (2007). The Effects of Costless Pre-play Communication: Experimental Evidence from Games with Pareto-ranked Equilibria. Journal of Economic Theory, 132(1), 274-290.

Bochet, O., Page, T. and Putterman, L. (2006). Communication and punishment in voluntary contribution experiments. Journal of Economic Behavior and Organization, 60, 11-26.

Bornstein, G., Budescu, D. and Shmuel, Z. (1997). Cooperation in Intergroup, N-Person and Two Person Games of Chicken. The Journal of Conflict Resolution, 41(3), 384-406.

Brandts J. and Cooper, D. (2007). It's What You Say, Not What You Pay: an Experimental Study of Manager - Employee Relationships in Overcoming Coordination Failure. Journal of the European Economic Association, 5(6), 1223-1268.

Bruttel, L. and Güth, W. (2013). Alternating or Compensating? An Experiment on the Repeated Sequential Best Shot Game. Max Planck Institute of economics, Jena, mimeo.

Cason, T. and Mui V-L. (2014). Coordination Resistance through Communication and Repeated Interaction. The Economic Journal, 124(574), 226-256.

Cason, T., Lau, S-H P. and Mui, V-L. (2013). Learning, Teaching, and Turn Taking in the Repeated Assignment Game. Economic Theory, 54, 335-357.

Charness, G. and Dufwenberg, M. (2006). Promises and Partnership. Econometrica, 74(6), 1579-1601.

Charness, G. and Gneezy, U. (2012). Strong Evidence for Gender Differences in RiskTaking. Journal of Economic Behavior \& Organization, 83, 50-58.

Cooper, D. J. and Kuhn, K. U. (2012). Communication, Renegociation, and the Scope for Collusion. Working paper.

Cooper, R., DeJong, D., Forsythe, R. and Ross, T. (1989). Communication in the Battle of the Sexes Game Some Experimental Results. The RAND Journal of Economics 20(4), 568-587.

Cooper, R., DeJong, D., Forsythe, R. and Ross, T. (1992). Communication in Coordination Games. Quarterly Journal of Economics, 107(2), 739-771.

Crawford, V. (1998). A Survey of Experiments on Communication via Cheap Talk. Journal of Economic Theory, 78, 286-298.

Dickhaut, J. W., Mccabe, K. A. and Mukherji, A. (1995). An Experimental Study of Strategic Information Transmission. Economic Theory, 6(3), 389-403.

Duffy, J. and Feltovich J. (2002). Do Actions Speak Louder than Words? An Experimental Comparison of Observation and Cheap Talk. Games and Economics Behavior, 39, 1-27. 
Duffy, J. and Hopkins E. (2005). Learning, Information, and Sorting in Market Entry Games: Theory and Evidence. Games and Economic Behavior, 51, 31-62.

Evans, S., Sibly, H. and Tisdell, J. (2013). Turn-Taking in Finitely Repeated Symmetric Games: Experimental Evidence. University of Tasmania, mimeo.

Farrel, J. and Rabin, M. (1996). Cheap Talk. Journal of Economic Perspectives, 10(3), 103118.

Fehr, E. and Schmidt, K. (1999). A Theory of Fairness, Competition, and Cooperation. Quarterly Journal of Economics, 114(3), 817-868.

Fischbacher, U. (2007). z-Tree: Zurich toolbox for ready-made economic experiments. Experimental Economics, 10(2), 171-178.

Gabszewicz, J. and Thisse, J. (1979). Price Competition, Quality and Income Disparities. Journal of Economic Theory, 20, 340-359.

Gneezy, U. and Potters, J. (1997). An experiment on Risk Taking and Evaluation Periods. Quarterly Journal of Economics, 112(2), 631-645.

Greiner, B. (2004). An online recruitment system for economic experiments. In Forschung und wissenschaftliches Rechnen GWDG Bericht 63, Ed. K. Kremer, and V. Macho. Göttingen: Gesellschaft für Wissenschaftliche Datenverarbeitung.

Helbing, D., Schönhof, M. and Stark, H-U. (2005). How Individuals Learn to Take Turns: Emergence of Alternating Cooperation in a Congestion Game the Prisonners Dilemma. Working paper.

Isaac, M.R. and Plott, C.R. (1981). The Opportunity for Conspiracy in Restraint of Trade: An Experimental Study. Journal of Economic Behavior \& Organization, 2(1), 1-30.

Isaac, M. R., Ramey, V. and Williams, A. (1984). The Effects of Market Organization on Conspiracies in Restraint of Trade. Journal of Economic Behavior \& Organization, 5(2), 191-222.

Isaac M.R. and Walker, J. M. (1985). Information and Conspiracy in Sealed-bid Auctions. Journal of Economic Behavior \& Organization, 6(2),139-159.

Justman, M., Thisse, J-F. and van Ypersele, T. (2005). Fiscal Competition and Regional Differentiation. Regional Science and Urban Economics, 35(6), 848-861.

Kaplan, T. R. and Ruffle, B. J. (2012). Which Way to Cooperate. The Economic Journal, 122 (563), 1042-1068.

Lau S-H P. and Mui, V-L. (2008). Using Turn Taking to Mitigate Coordination and Conflict Problems in the Repeated Battle of the Sexes Game. Theory and Decision, 65(2), 153183.

Lau S-H P. and Mui, V-L. (2012). Using Turn Taking to Achieve Intertemporal Cooperation and Asymmetry in Infinitely Repeated 2x2 games. Theory and Decision, 72, 167-188.

Ledyard, J.O. (1995). Public Goods: A Survey of Experimental Research, in J. H. Kagel and A. E. Roth, Handbook of Experimental Economics. Princeton: Princeton University Press, 94-111

Leibbrandt, A. and Sääksvuori, L. (2012). Communication in Intergroup Conflicts. European Economic Review, 56, 1136-1147.

Ostrom, E. (1990). Governing the commons: The evolution of institutions for collective action. New-York: Cambridge University Press. 
Sally, D. (1995). Conversation and Cooperation in Social Dilemmas: A Meta-analysis of Experiments from 1958 to 1992. Rationality and Society, 7(1), 58-92.

Shaked, A. and Sutton, J. (1982). Relaxing Price Competition through Product

Differentiation. Review of Economics Studies, 3-13.

Zillante, A., (2011). Recognizing and playing turn taking strategies. UNC Charlotte, mimeo. 
Appendix 1. Extensive form of the two-stage coordination game

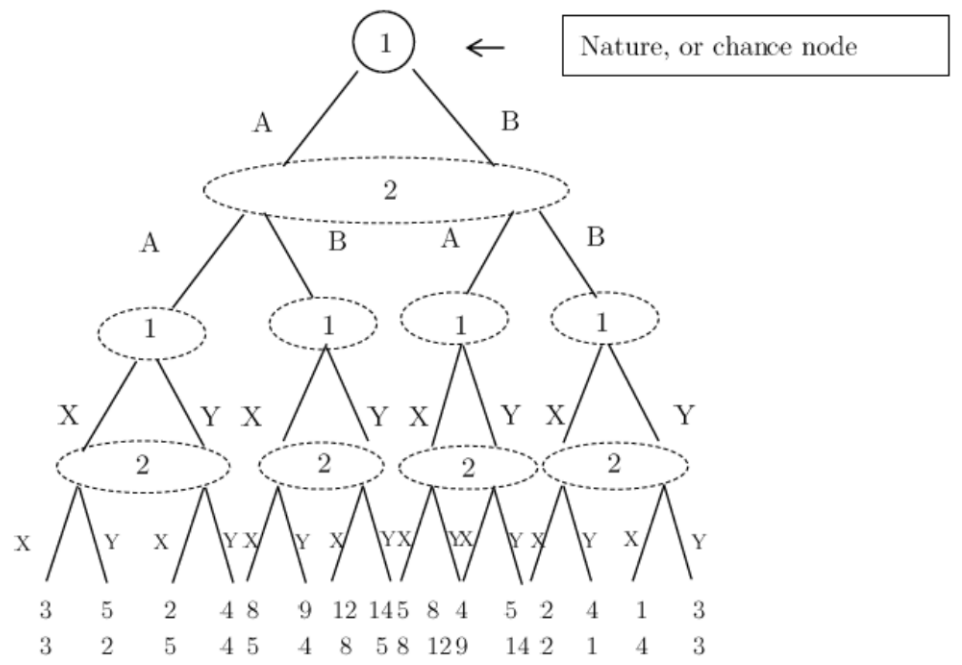

Extensive form of the two-stage coordination game 


\section{Appendix 2 Instructions (translated from French)}

The following instructions are for the Baseline treatment. We add the instructions that are specific to the communication treatments in italics into brackets. The instructions for the additional part of the One-Way treatment are shown after the instructions for the other treatments.

\section{General information}

We thank you for participating in this experiment in economics. Your payoffs depend on your decisions. It is therefore important that you read the following instructions carefully.

Instructions are distributed for your personal use. We thank you for not communicating with other participants during the experiment unless you are invited to do so. All your decisions are anonymous: you will never enter your name into the computer during the experiment.

The experiment is divided into two independent parts. [This sentence is replaced by the following in the One-Way treatment: The experiment is divided into three parts. The first part is independent of the following parts.] First, we will explain the first part. Once the first part is completed, you will receive detailed information for the second part.

During the experiment, we will not talk about Euros but about ECU (Experimental Currency Units). All payoffs will be calculated in ECU. The conversion rate between ECU and Euros is:

$$
100 \text { ECU }=5 \text { Euros }
$$

At the end of the experiment, the total number of ECU that you earned in each part will be converted into Euros. In addition to this amount, you will receive a show up fee of 4 Euros.

All payments will be made in private and in cash in a separate room. Other participants will never know the amount of your payoffs in this experiment.

\section{Part 1}

\section{Description of the task}

You will receive 80 ECU. We ask you to choose an amount in ECU (between 0 and 80 ECU included) that you are willing to invest in a risky asset. You keep for yourself the ECU that are not invested.

\section{The investment}

There is one chance out of two that the investment is a success.

If this is a success, you will receive two and a half times the amount you have invested.

If the investment is not a success, you will lose the amount you invested.

1st example: You invest 0 ECU. You earn: $(80-0)=80$ ECU.

2nd example: You invest 40 ECU. If the investment is a success, you earn $(80-40)+2.5 * 40=140$. If the investment is not a success, you earn (80-40) $+0=40$ ECU.

3rd example: You invest $80 \mathrm{ECU}$. If the investment is a success, you earn $(80-80)+2.5 * 80=200$. If the investment is not a success, you earn $(80-80)+0=0$ ECU.

\section{How do we determine if the investment is a success?}

We ask you to choose a color: black or white.

At the end of the session, the computer program will randomly select one of these two colors. Each color has the same chance of being selected.

If the randomly selected color is the one you have chosen, the investment is a success.

If the randomly selected color is not the one you have chosen, the investment is not a success. 
You will be informed of your payoff in this first part only at the end of the session.

To sum up: You have to choose now the amount you wish to invest and the color. At the end of the session, the program will randomly select a color for all the participants and it will indicate to you the color randomly selected as well as your payoff for this part that will be added to your payoffs of the second part.

Please read these instructions. If you have any question about these instructions, please raise your hand and we will answer these questions in private.

Part 2 (distributed after completion of Part 1)

This part includes 20 independent periods.

Before the beginning of the first period, the computer program will randomly divide the participants in this session between Red participants and Blue participants. There are as many Red participants as Blue participants.

During these 20 periods, you will be either a Blue participant or a Red participant. You will keep the same color throughout the whole session. You will be informed of your color before the beginning of the first period.

At the beginning of this part, the computer program will form pairs composed of a Blue participant and a Red participant. You will be randomly paired with another participant in this session who has a different color from yours. You will remain paired with the same co-participant during the 20 periods. You will never know the identity of your co-participant.

\section{Description of each period}

Each period consists of two stages. During each of the two stages you will have to choose between two options.

[Two-Way treatment: At the beginning of each period, before starting the first stage, you can communicate with your co-participant. A dialog box will appear on your screen for this purpose. For a maximum of 1 minute, you can use this box to exchange messages with your co-participant. Your messages should not include information that identifies you or your coparticipant. They must not contain rude language or threats.

If you want to stop the communication before the minute has elapsed, press the "OK" button. Once you or your co-participant press the "OK" button, the dialog box is no longer available and the next screen appears at the same time for both co-participants. As soon as one of you press the "OK" button it is no longer possible to send messages. If you do not press the "OK" button, the dialog box closes automatically after one minute, and the next screen appears. ]

\section{Stage 1}

You have to choose between option A and option B. Your co-participant also chooses between these two options simultaneously.

Once you and your co-participant have made your choices, you will be informed of the choice of your co-participant and your co-participant will be informed of your choice.

\section{Stage 2}

You have to choose between option $\mathbf{X}$ and option Y. Your co-participant also chooses between these two options simultaneously.

Once you and your co-participant have made your choices, you will be informed of the choice of your co-participant and your co-participant will be informed of your choice. You are then informed 
of your payoff and of the payoff of your co-participant. The period ends and another period starts automatically.

\section{Calculation of payoffs}

Your payoffs and the payoffs of your co-participant in the period depend on the choices between options A and B and between options X and Y. Table 1, in the attached sheet, represents all possible payoffs in a period. Please refer to this table.

Table 1 shows in red the choice (A, B, X, Y) and the possible payoffs of the Red participant in the period. It shows in blue the choices $(\mathrm{A}, \mathrm{B}, \mathrm{X}, \mathrm{Y})$ and the possible payoffs of the Blue participant in the period.

At the end of stage 1, one of the following four situations is possible:

- Both participants chose option A

- Both participants chose option B

- The Red participant chose option A and the Blue participant chose option B

- The Red participant chose option B and the Blue participant chose option A.

At the beginning of stage 2, only one of the 4 panels of Table 1 will be used to determine your payoffs for the period given your choice and the choice of your co-participant between options $\mathrm{X}$ and $\mathrm{Y}$. We describe below the four possible cases, each case refers to a table in the attached sheet.

a) If both participants chose option $A$ in stage 1, Table 2 describes the possible payoffs given the choices made between $\mathrm{X}$ and $\mathrm{Y}$ in stage 2. Please refer to it.

Table 2 reproduces the North West panel of Table 1. Four situations are possible at the end of stage 2:

- Both participants chose option X. The Red participant earns 3 ECU and the Blue participant earns 3 ECU.

- Both participants chose option Y. The Red participant earns 4 ECU and the Blue participant earns 4 ECU.

- The Red participant chose option X and the Blue participant chose option Y. The Red participant earns $5 \mathrm{ECU}$ and the Blue participant earns $2 \mathrm{ECU}$.

- The Red participant chose option Y and the Blue participant chose option X. The Red participant earns $2 \mathrm{ECU}$ and the Blue participant earns $5 \mathrm{ECU}$.

b) If both participants chose option $B$ in stage 1, Table 3 describes the possible payoffs given the choices made between $\mathrm{X}$ and $\mathrm{Y}$ in stage 2 .

Table 3 reproduces the South East panel of Table 1. Four situations are possible at the end of stage 2:

- Both participants chose option X. The Red participant earns 2 ECU and the Blue participant earns 2 ECU.

- Both participants chose option Y. The Red participant earns 3 ECU and the Blue participant earns 3 ECU.

- The Red participant chose option X and the Blue participant chose option Y. The Red participant earns $4 \mathrm{ECU}$ and the Blue participant earns $1 \mathrm{ECU}$.

- The Red participant chose option Y and the Blue participant chose option X. The Red participant earns $1 \mathrm{ECU}$ and the Blue participant earns $4 \mathrm{ECU}$. 
c) If the Red participant chose Option $A$ and the Blue participant chose option B, Table 4 describes the possible payoffs given the choices made between $\mathrm{X}$ and $\mathrm{Y}$ in stage 2 .

Table 4 reproduces the North East panel of Table 1. Four situations are possible at the end of stage 2: - Both participants chose option X. The Red participant earns 8 ECU and the Blue participant earns 5 ECU.

- Both participants chose option Y. The Red participant earns 14 ECU and the Blue participant earns 5 ECU.

- The Red participant chose option X and the Blue participant chose option Y. The Red participant earns $9 \mathrm{ECU}$ and the Blue participant earns $4 \mathrm{ECU}$.

- The Red participant chose option Y and the Blue participant chose option X. The Red participant earns $12 \mathrm{ECU}$ and the Blue participant earns $8 \mathrm{ECU}$.

d) If the Red participant chose option $B$ and the Blue participant chose option A, Table 5 describes the possible payoffs given choices made between $\mathrm{X}$ and $\mathrm{Y}$ in stage 2 .

Table 5 reproduces the South West panel of Table 1. Four situations are possible at the end of stage 2:

- Both participants chose option X. The Red participant earns 5 ECU and the Blue participant earns 8 ECU.

- Both participants chose option Y. The Red participant earns 5 ECU and the Blue participant earns 14 ECU.

- The Red participant chose option X and the Blue participant chose option Y. The Red participant earns $8 \mathrm{ECU}$ and the Blue participant earns $12 \mathrm{ECU}$.

- The Red participant chose option Y and the Blue participant chose option X. The Red participant earns 4 ECU and the Blue participant earns 9 ECU.

At the end of stage 2, you will be informed of the choice of your co-participant, of your payoff and of the payoff of your co-participant in this period. The next period will start automatically.

You have at your disposal on your desk a history table that allows you to take notes on your decisions and the decisions of your co-participant and on the associated payoffs in each period.

\section{End of the part}

At the end of the 20 periods, you will be informed of your total payoff in this part. Your total payoff in this part is the sum of your payoffs in each of the 20 periods.

Then, a final questionnaire will appear on your screen. Afterwards, you will be informed when to go to the payment room.

Please read again these instructions. If you have any question, raise your hand and we will answer to your questions in private. Thank you to fill out the understanding questionnaire that has been distributed. We will come to you to check your answers in private. 
Table 1. Payoffs with options A, B, X and $\mathrm{Y}$ at the beginning of stage 1

\begin{tabular}{|c|c|c|c|c|c|c|}
\hline \multirow{3}{*}{\multicolumn{3}{|c|}{ 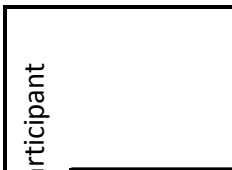 }} & \multicolumn{4}{|c|}{ Choices of the blue participant } \\
\hline & & & \multicolumn{2}{|c|}{ A } & \multicolumn{2}{|c|}{ B } \\
\hline & & & $\mathbf{x}$ & $\mathbf{Y}$ & $\mathbf{x}$ & $\mathbf{Y}$ \\
\hline \multirow{4}{*}{$\frac{2}{0}$} & \multirow{2}{*}{ A } & $x$ & $3 ; 3$ & $5 ; 2$ & $8 ; 5$ & $9 ; 4$ \\
\hline & & $\mathrm{Y}$ & $2 ; 5$ & $4 ; 4$ & $12 ; 8$ & $14 ; 5$ \\
\hline & \multirow{2}{*}{ B } & $\mathrm{x}$ & $5 ; 8$ & $8 ; 12$ & $2 ; 2$ & $4 ; 1$ \\
\hline & & $Y$ & $4 ; 9$ & $5 ; 14$ & $1 ; 4$ & $3 ; 3$ \\
\hline
\end{tabular}

Table 2. Payoffs with options $\mathrm{X}$ and $\mathrm{Y}$ when both participants chose $\mathrm{A}$ in stage 1

\begin{tabular}{|c|c|c|c|}
\hline \multirow{4}{*}{ 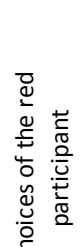 } & \multicolumn{3}{|c|}{$\begin{array}{l}\text { Choices of the blue } \\
\text { participant }\end{array}$} \\
\hline & & $X$ & $Y$ \\
\hline & $x$ & $3 ; 3$ & $5 ; 2$ \\
\hline & $Y$ & $2 ; 5$ & $4 ; 4$ \\
\hline
\end{tabular}

Table 3. Payoffs with options $\mathrm{X}$ and $\mathrm{Y}$ when both participants chose $\mathrm{B}$ in stage 1

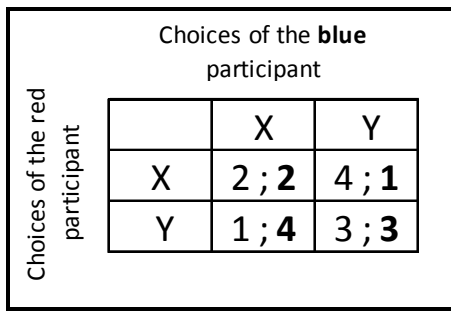

Table 4. Payoffs with options $\mathrm{X}$ and $\mathrm{Y}$ when Red chose A and Blue chose B in stage 1

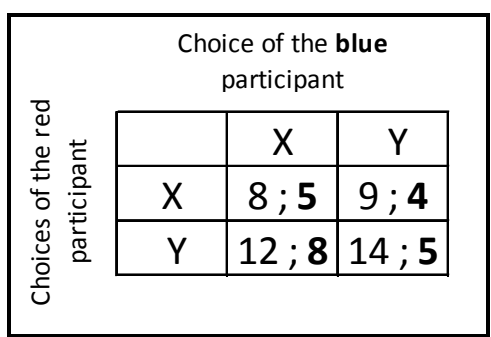

Table 5. Payoffs with options $\mathrm{X}$ and $\mathrm{Y}$ when Red chose $\mathrm{B}$ and Blue chose $\mathrm{A}$ in stage 1

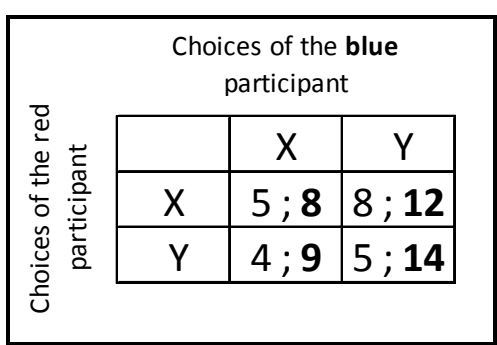




\section{Part 2}

In this part, we ask you to perform a task. Your score in this task will be compared to the scores of the other participants and it will be used to determine your role in the next part, as explained below.

\section{Description of the task}

At the beginning of this part your screen will show 16 black rectangles, as shown in the figure below:

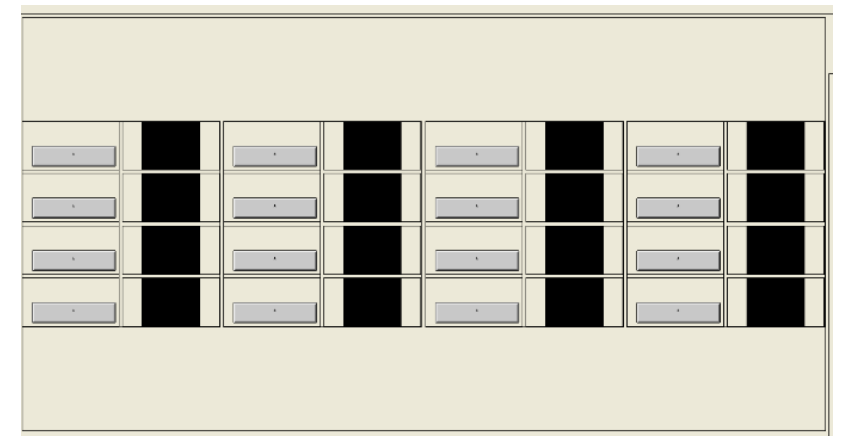

On the screen, the 16 black rectangles hide 8 pairs of identical images. The task is to reform a maximum of pairs of identical images for a period of 5 minutes. You score 1 point each time you form a pair of identical images, as shown in the figure below.

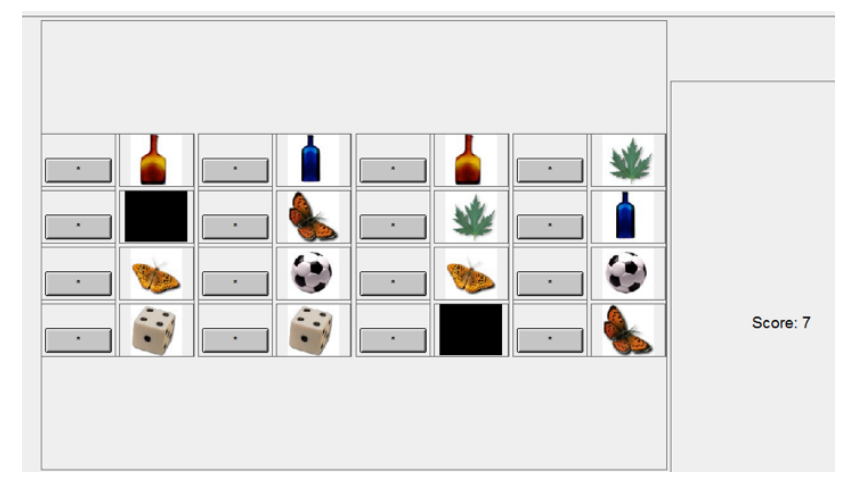

To see the image that hides behind a black rectangle, press the gray button to the left of the black rectangle. The first uncovered image remains visible while you are uncovering a second image. You can press gray buttons as many times as you want but you can only see two images at once.

If the two images you just uncovered are not identical, they disappear again behind black rectangles after half a second. When two identical images are displayed at the same time, your score increases by 1 point and the 2 identical images remain permanently visible. To facilitate the search for pairs of identical images, you should try to memorize the images already uncovered behind the black rectangles.

Once you have uncovered the 8 pairs of images on the screen, a new screen appears with the same images, but arranged randomly in a different way. These images include a ball, a die, two kinds of butterflies, two types of bottles and two kinds of leaves.

Your total score in this part is given by the number of pairs of identical images you have been able to reform during 5 minutes.

To familiarize yourself with the task, you will have the chance to train for two minutes. At the end of this training period, the part will start automatically. 


\section{Relative performance}

At the end of this part the computer program will compare the scores of the participants in the room. It will define two groups according to the scores. One group will be composed of the half of participants who have the highest scores and the other group will be composed of the half of participants who have the lowest scores. Depending on your score you will be assigned to one of the two groups and your role will be different in the third part of this experiment. Please read again these instructions. If you have any question, please raise your hand and we will answer to you in private.

Part 3 (distributed after completion of Part 2)

This part includes 20 independent periods.

At the beginning of this part, the computer program will form pairs. You will be randomly paired with another participant in this session. You will remain paired with the same co-participant during the 20 periods. You will never know the identity of your co-participant.

Within each pair, one of the participants will be able to send messages to the other participant at the beginning of each period. It is always the same participant who will be able to send messages to the other.

To determine the participants who can send the messages, the computer program rank participants in this session based on the scores achieved in part 2. It forms two groups of equal size according to the scores achieved. Participants who belong to the group that made the highest scores in Part 2 will be allowed to send messages to their co-participant who belongs to the other group.

In addition, before the beginning of the first period, the computer program will randomly divide the participants in this session between Red and Blue participants. There are as many Red participants as Blue participants. Each pair consists of a Red participant and a Blue participant. Thus, during these 20 periods, you will either be a Blue participant or a Red participant. You will keep the same color throughout the session. In the pair, the participant who can send messages to the other participant can be either the Red participant or the Blue participant. The color assignment is independent of the ability to send messages.

You will be informed of your color before the beginning of the first period. The program will also inform you whether you are or not allowed to send messages to your co-participant, as explained below.

\section{Description of each period}

Each period consists of two stages. During each of the two stages you will have to choose between two options.

At the beginning of each period, before starting the first stage, if you are the participant who can send messages to your co-participant, you can communicate with your co-participant. A dialog box will appear on your screen for this purpose. For a maximum of 20 seconds, you can use this box to send messages to your co-participant. Messages should not include information that identifies you or your co-participant. They must not contain rude language or threats.

If you want to stop the communication before the 20 seconds have elapsed, press the "OK" button. Once you have pressed the "OK" button, the dialog box is no longer available and the next screen appears at the same time for both co-participants. If you do not press the "OK" button, the dialog box closes automatically after 20 seconds, and the next screen appears.

If you are the participant who is not allowed to send a message to your co-participant, you will see your co-participant's messages appear in the dialog box on your screen. However, you cannot respond.

\section{The rest of the instructions is similar to the other treatments.}




\section{Appendix 3. Figures of pair decisions}

Figure A1. Mean first stage choices between A and B, by pair and by period, Baseline

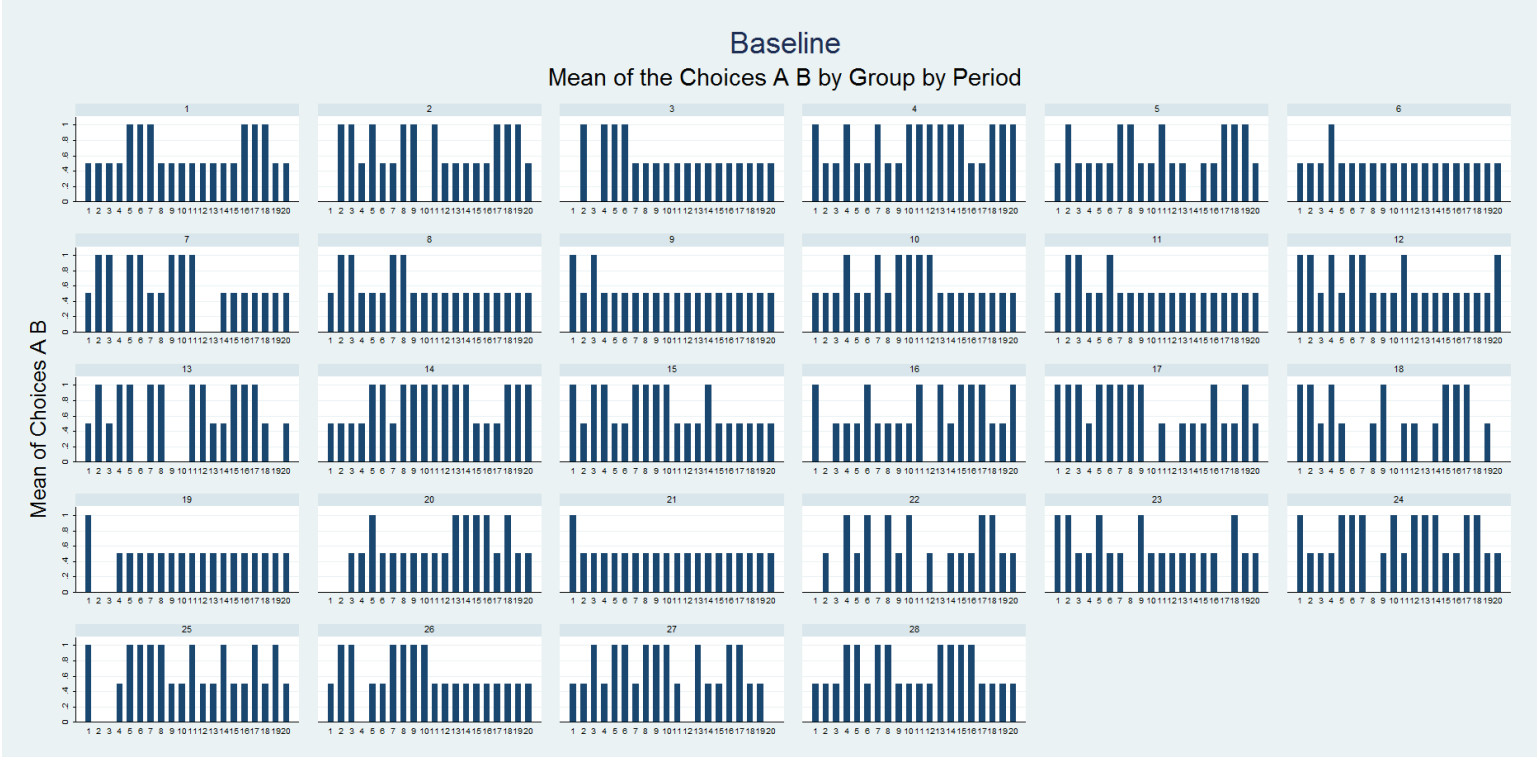

Note: This graph displays the first-stage choices of each pair in each of the 20 periods. Choosing A corresponds to 1 , choosing B corresponds to 0 . Thus, a mean choice between A and B equal to 0.5 means that the two players in the pair have chosen opposite options.

Figure A2. Mean first stage choices between A and B, by pair and by period,

Two-Way treatment

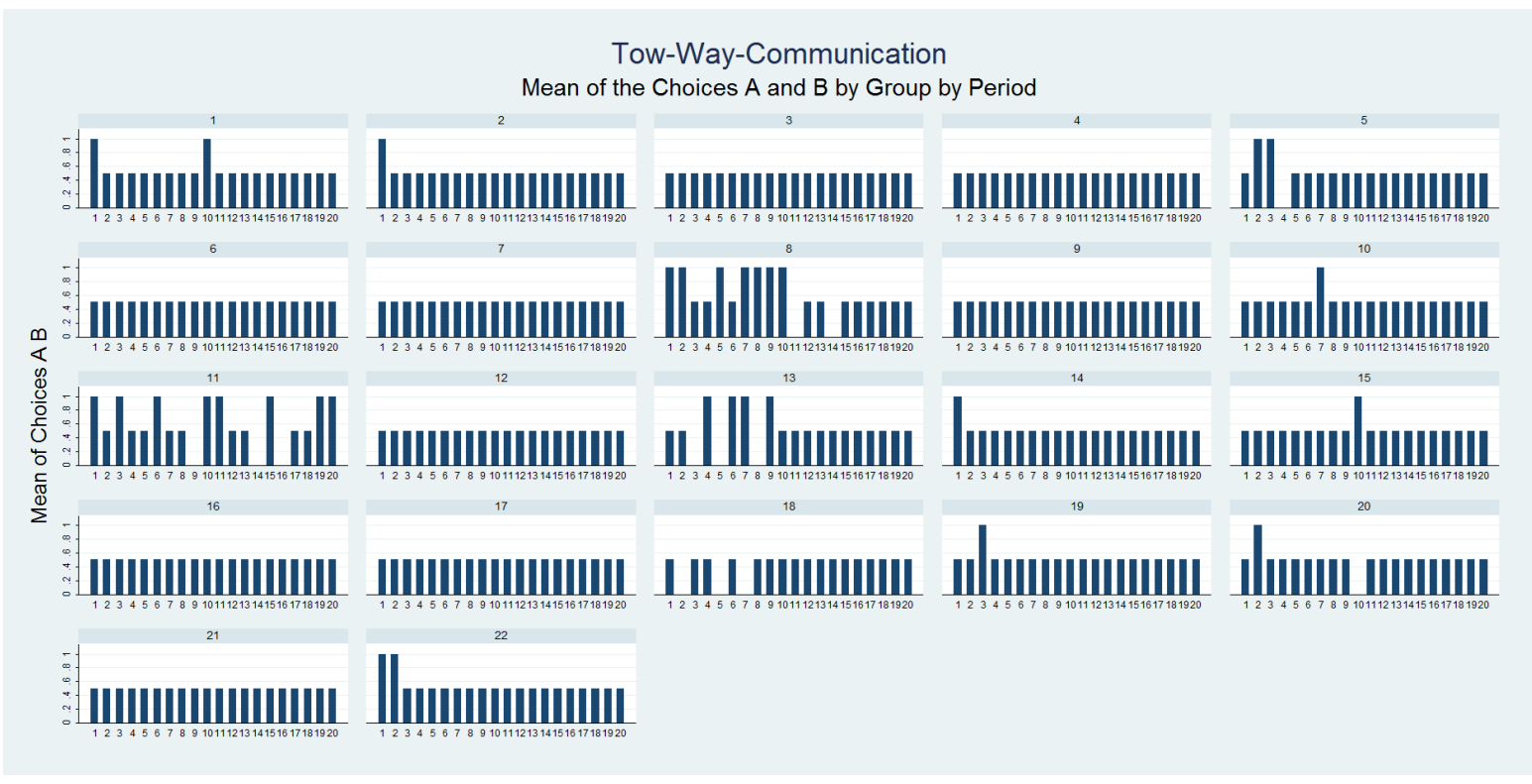


Figure A3. Mean first stage choices between A and B, by pair and by period, One-Way treatment

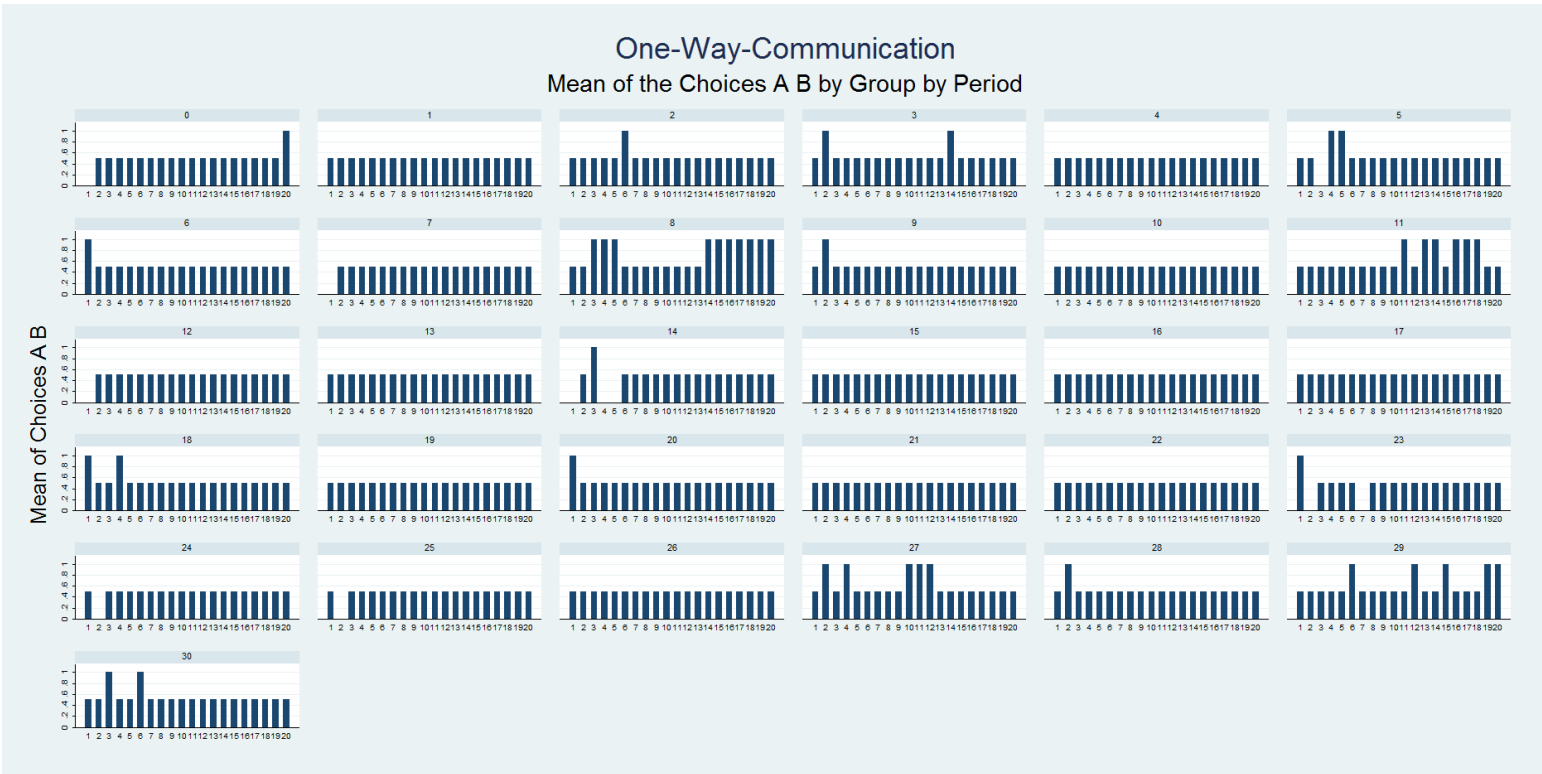

Figure B1. Mean strategies in the two stages, by pair and by period, Baseline

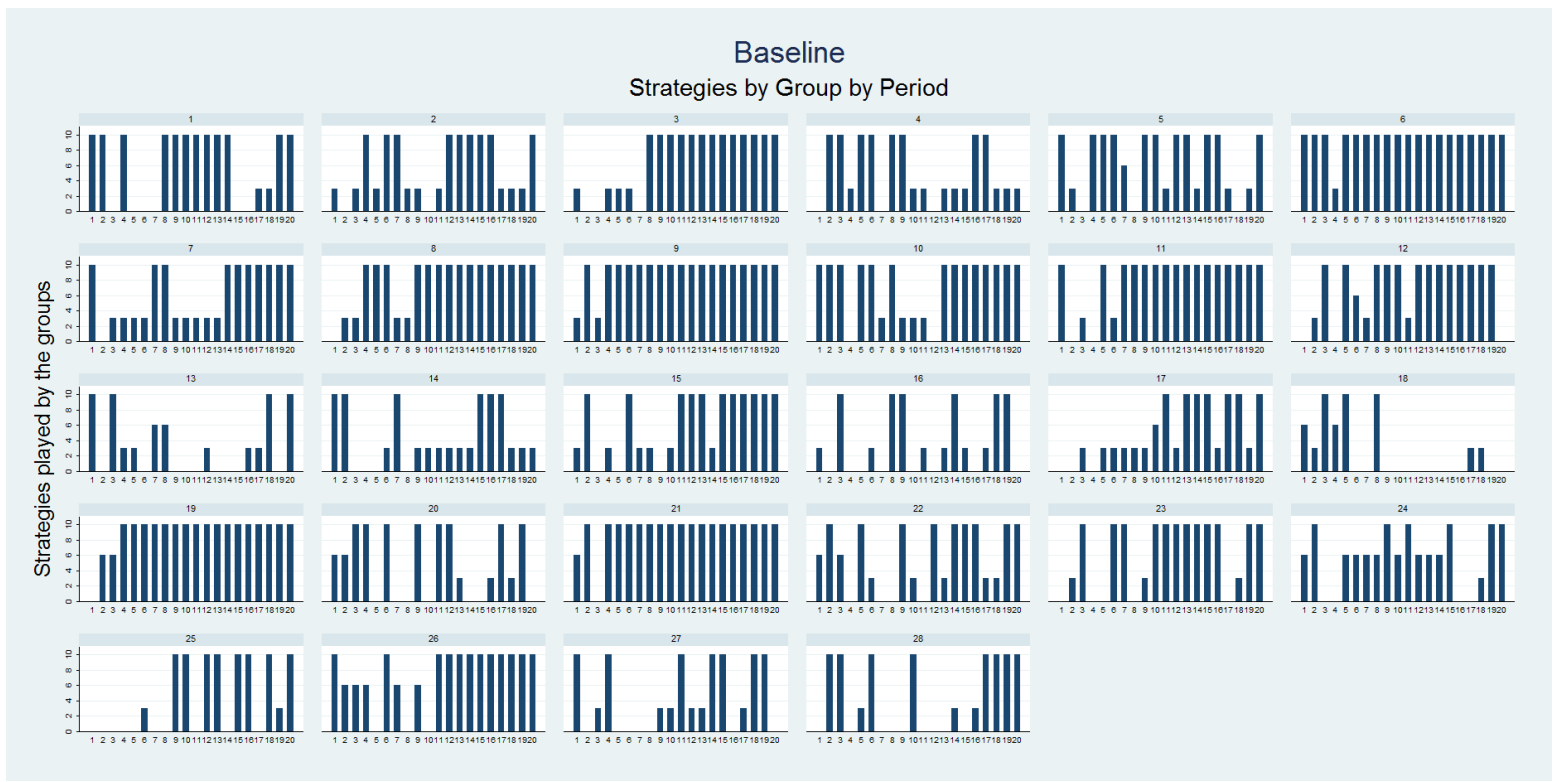

Note: This graph displays the two-stage strategy of each pair in each of the 20 periods. The values on the scale are arbitrary. Value 10 means that the pair chose opposite options in both the first and the second stages; they played the Subgame Perfect Nash Equilibrium. Value 6 means the two pair members have chosen the same option in the first stage and they played Pareto optimally in the second stage instead of following their dominant strategy. Value 3 indicates that after choosing the same option in the first stage, the two pair members played their dominant strategies in the second stage of the game. We set 0 for all the other strategies. 
Figure B2: Mean strategies in the two stages, by pair and by period, Two-Way-Communication

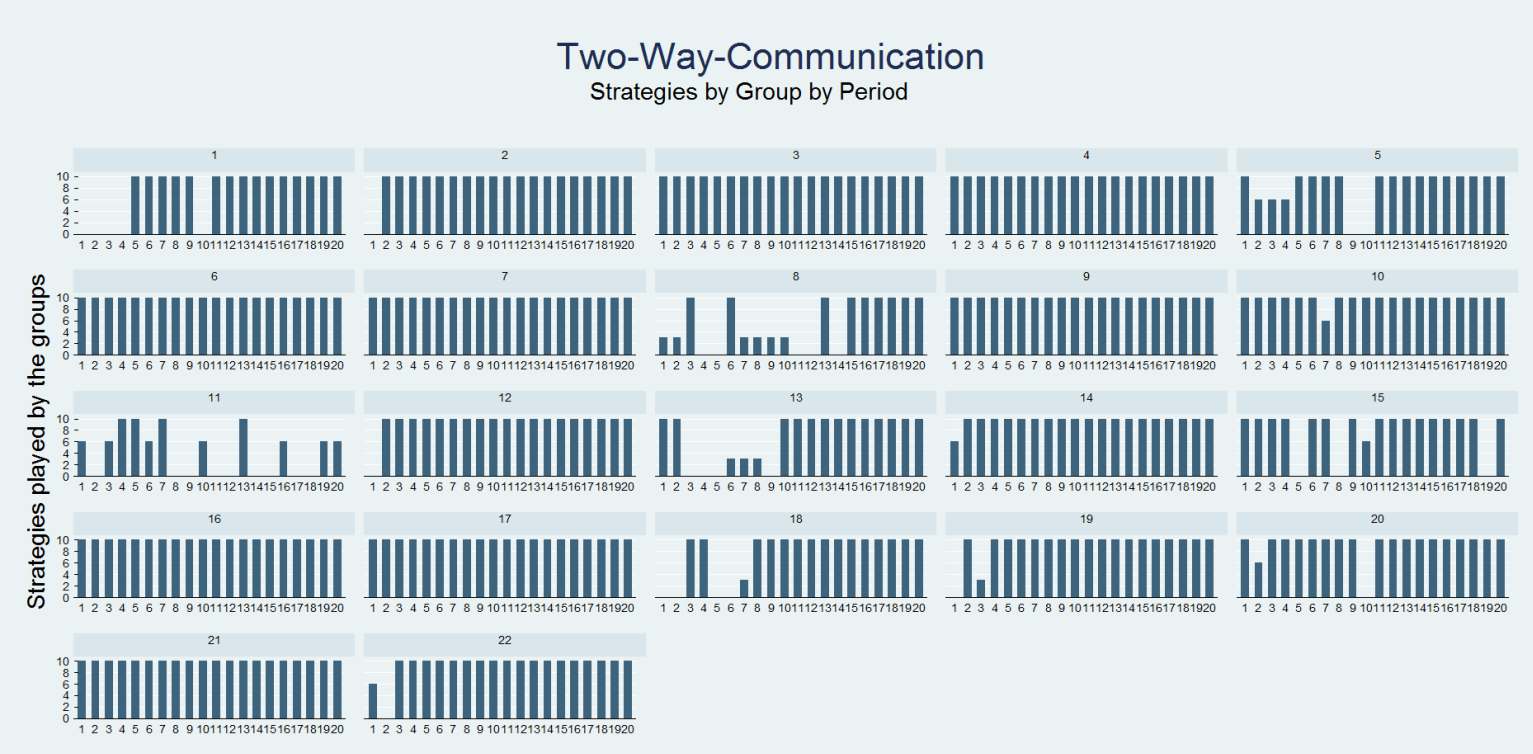

Figure B3: Mean strategies in the two stages, by pair and by period,

One-Way-Communication

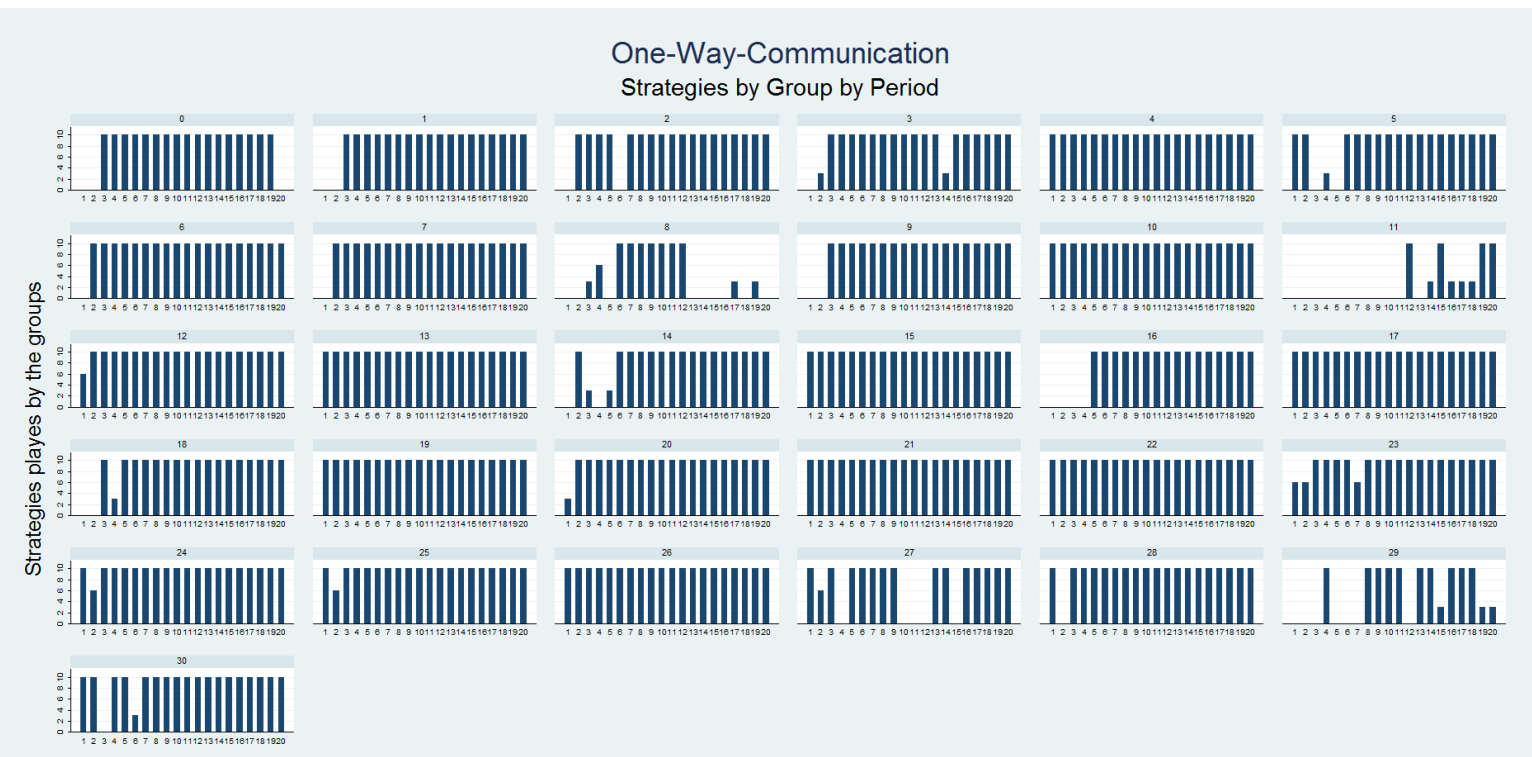

